\title{
AUTOMATED CAVITY RING DOWN SPECTROSCOPY USAGE FOR NITROUS OXIDE EMISSION MEASUREMENTS FROM SOIL USING RECIRCULATION SYSTEM
}

\author{
Inga Grinfelde, Kristine Valujeva, Karina Zaharane, Laima Berzina \\ Latvia University of Agriculture \\ inga.grinfelde@1lu.lv
}

\begin{abstract}
The nitrous oxide accounted for the year 2015 gives $60 \%$ of Latvia`s greenhouse gas emissions from the agricultural sector. Majority of nitrous oxide comes from mineral fertiliser application and manure management. Nitrous oxide emission from soils is strongly correlated with the soil moisture and temperature. Since nitrous oxide has very low concentrations in natural environment, there is a risk to overestimate or underestimate nitrous oxide emission. Automated cavity ring down spectroscopy for nitrous oxide emission measurements is a relatively new technology and there is a need for development of proper methodology. The aim of this study is to identify proper measurement time for nitrous oxide emission from soil by using automated cavity ring down spectroscopy with recirculation system. The automated cavity ring down spectroscopy, namely Picarro G2508, was connected in a closed recirculation system with the chamber of total volume 2 litres. Dray soil samples were weighted in containers and different amounts of water and ammonium nitrate were added. Totally 36 samples were used in the experiment. Each sample was measured 10 minutes and the nitrous oxide concentration was recorded for each second. For each sample measurements were repeated three times. The linear regression method was used to calculate the emission amount for different time periods from 30 seconds till 600 seconds. The results of the research show quite high variation of nitrous oxide emission from the soil samples. Data analysis showed that the minimal measurement time has to be at least 250 seconds.
\end{abstract}

Keywords: CRDS, Picarro G2508, chamber enclosure time.

\section{Introduction}

The measurements of nitrous oxide $\left(\mathrm{N}_{2} \mathrm{O}\right)$ emissions have become an actual topic during the last 20 years[1]. $\mathrm{N}_{2} \mathrm{O}$ emissions from soil are measured by using closed static chembers [2]. The cavity ring down spectroscopy (CRDS) has pre-eminent detection limit and high precision [3; 4]. However, the CRDS device Picarro G2508 is limited by one outlet [5]. The chamber enclosure time is limitation for the experiment design. The $\mathrm{N}_{2} \mathrm{O}$ concentration in atmosphere is $0.325 \mathrm{ppm}$ [6] and during the measurement $\mathrm{N}_{2} \mathrm{O}$ fluctuated. The measurement error of $\mathrm{N}_{2} \mathrm{O}$ is $0.005 \mathrm{ppm}$ [5]. The fluctuaction of $\mathrm{N}_{2} \mathrm{O}$ is related with concentrations of other gases as well as climatic factors. The previous research shows that appropriate chamber closure time for measurements with CRDS is from 200 till 400 seconds [3].

The aim of this study is to identify the GHG measurement time for cavity ring down spectroscopy Picarro G2508 by using the recyrculation system for soil flux experiments in laboratory conditions.

\section{Materials and methods}

The experiment was conducted in laboratry conditions with fixed air temperature, air presure and humidity. 36 soil samples with weight of $100 \mathrm{~g}$ and moisture of $20 \%$ were colected in plastic containers. The amonia nitrate dosings were $0 \mathrm{~g}, 1 \mathrm{~g}, 2 \mathrm{~g}, 3 \mathrm{~g}, 4 \mathrm{~g}$ and $5 \mathrm{~g}$. The water dosings were $0 \mathrm{ml}, 10 \mathrm{ml}, 20 \mathrm{ml}, 30 \mathrm{ml}, 40 \mathrm{ml}$ and $50 \mathrm{ml}$. Water and amonia nitrate in each sample were added before the measurement. The CRDS device Picarro G2508 was connected with the chamber by using zero leaching conectors and the zero leaching external vacuum pump Picarro [5]. Each soil sample with the container were inserted into the chamber. After closure of the chamber, the gas concentrations of $\mathrm{N}_{2} \mathrm{O}$ were measured for 600 seconds. The gas concentration data of the 600 seconds period for each sample of each gas were used for further data analysis. The slope of concentration change is the main parameter for further calculations of GHG emmisions from soil. The linear regression (1) was used to calculate the slope of concentration fluctuactions for each data set.

$$
C=S \cdot T+c,
$$

where $C$-concentrations, ppm;

$S$ - slope, $\mathrm{ppm} \cdot \mathrm{s}^{-1}$;

$T$ - time, s;

$c$-intercept, ppm. 
The slope (2) of linear regression and the coefficient of determination (3) were calculated for 1 minute $(n=60)$ time period by using a step of 1 second. 286 slopes and coefficients of determination were calculated for each sample. The same procedure were repeated for 4 minutes $(n=240)$ time period by using slope calculation for each sample. 160 slopes and coefficients of determination were calculated for 4 minutes time period.

$$
S=\frac{n \sum(T C)-\sum T \sum C}{n \sum\left(T^{2}\right)-\left(\sum T\right)^{2}}
$$

where $n$-count of measurements;

Coefficient of determination $\left(R^{2}\right)$ was calculated as follows:

$$
R^{2}=\left(\frac{n \sum(T C)-\sum T \sum C}{\sqrt{\left[n \sum\left(T^{2}\right)-\left(\sum T\right)^{2}\right]\left[n \sum\left(C^{2}\right)-\left(\sum C\right)^{2}\right]}}\right)^{2}
$$

The slope (2) and coefficient of determination (3) values were used to calculate the slope (5) and relative changes of the determination coefficient per time unit (4):

$$
\Delta R^{2}=\frac{R_{i-1}^{2}-R_{i}^{2}}{R_{i}^{2}} \cdot 100
$$

where $\Delta R^{2}$ - relative change of determination coefficient, $\%$;

$i$ - current observation

$$
\Delta S=\frac{S_{i-1}-S_{i}}{S_{i}} \cdot 100
$$

where $\Delta S$ - relative change of slope, $\%$.

The calculated relative changes of slope and coefficient of determination in time unit were used for further analysis by using XLSTAT program package.

\section{Results and discussion}

The measurement session was done at $25^{\circ} \mathrm{C}$ soil and air temperature and the air pressure 1032 bar. The $\mathrm{N}_{2} \mathrm{O}$ concentrations of 36 soil samples were verifyed for slope and $R^{2}$ calculations. The descriptive statistics of the $\mathrm{N}_{2} \mathrm{O}$ concentration data is presented in Table 1 . The total number of the analysed $\mathrm{N}_{2} \mathrm{O}$ concentration data is 14,405 . There are no missing values. The mean concentrattion of $\mathrm{N}_{2} \mathrm{O}$ is $0.348 \mathrm{ppm}$, the standart deviation is $0.014 \mathrm{ppm}$.

Descriptive statistics of $\mathrm{N}_{2} \mathrm{O}$ concentration data

\begin{tabular}{|c|c|c|}
\hline Nr. & Statistic & $\mathbf{N}_{\mathbf{2}} \mathbf{O}, \mathbf{p p m}$ \\
\hline 1. & Number of observations & 14,405 \\
\hline 2. & Number of missing values & 0 \\
\hline 3. & Minimum & 0.215 \\
\hline 4. & Maximum & 0.407 \\
\hline 5. & Range & 0.192 \\
\hline 6. & 1st Quartile & 0.339 \\
\hline 7. & Median & 0.347 \\
\hline 8. & 3rd Quartile & 0.356 \\
\hline 9. & Mean & 0.348 \\
\hline 10. & Variance $(n-1)$ & 0.000 \\
\hline 11. & Standard deviation $(n-1)$ & 0.014 \\
\hline
\end{tabular}


The relative change of slope was analysed on one second step base. The 36 relative slope change data points were analysed for each second. The mean of the relative change of slope is not stable and it is fluctuating between $20 \%$ and $-20 \%$ (see Figure 1).

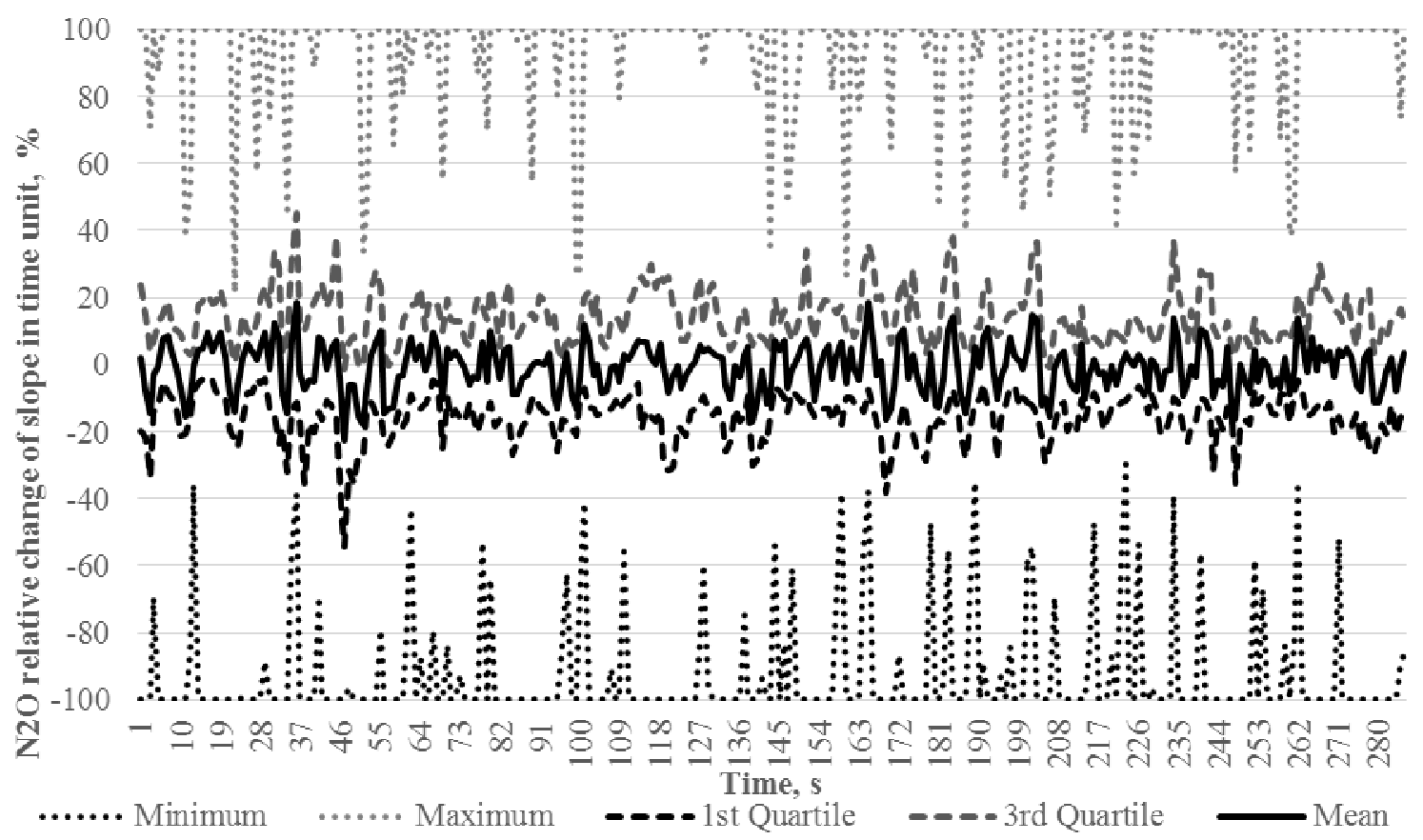

Fig. 1. Relative change of slope for 1 minute slope calculation period

The $1^{\text {st }}$ quartile and $3^{\text {rd }}$ quartile are close to mean, but the fluctuaction amplitude is between $40 \%$ and $-40 \%$. The minimal and maximal values are close to $100 \%$ and $-100 \%$. The relative change of slope was analysed for 4 minutes time period and it showed acceptable satbilistation of the slope change. The amplitude is between $20 \%$ and $-20 \%$ (see Figure 2).

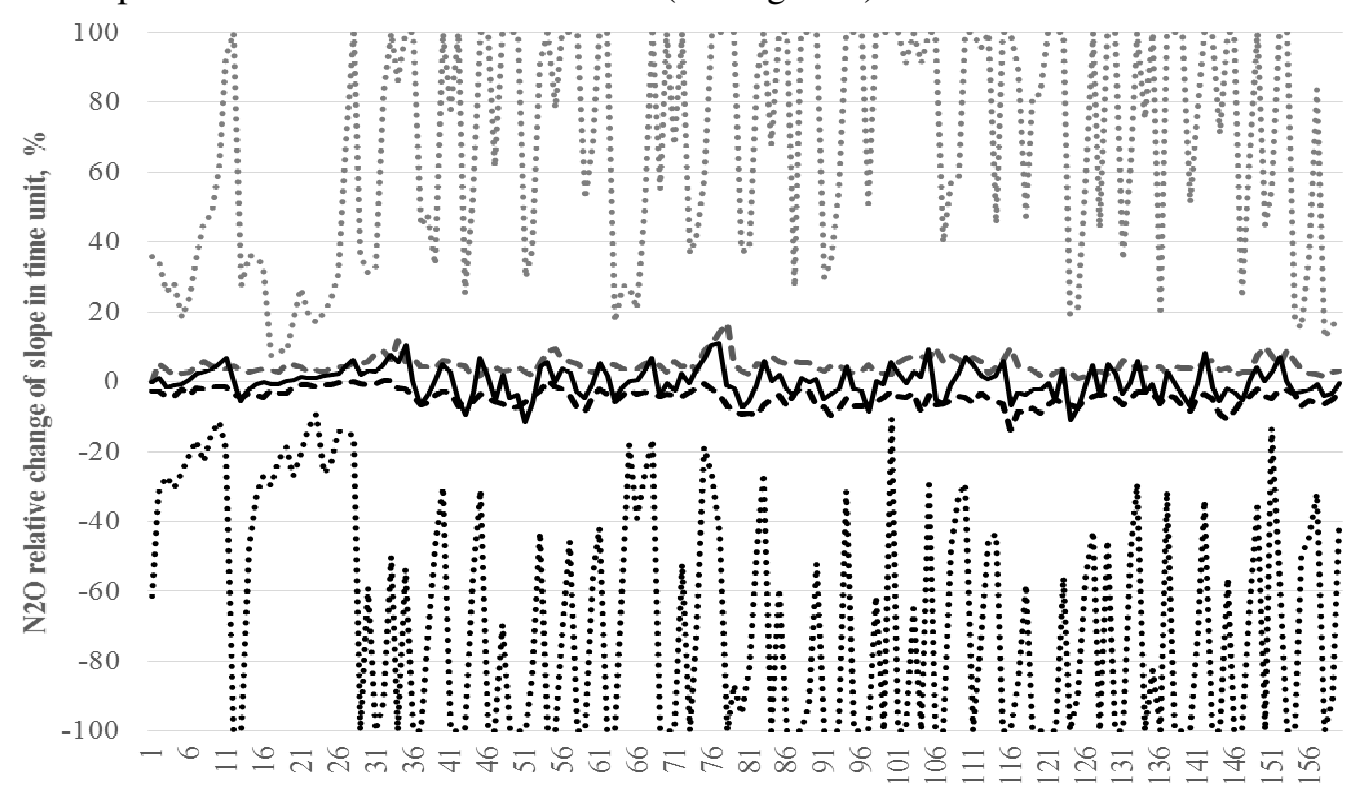

Time, s

..... Minimum

Maximum

-- - 1st Quartile

---3 rd Quartile

- Mean

Fig. 2. Relative change of slope for $\mathbf{4}$ minutes slope calculation period

However, there are still high maximal and minimal values of the relative slope change. The relative change of the determination coefficient is analysed on one second step base. 36 relative changes of data point of the coefficient of determination were analysed for each second. The mean of 
the relative change of the coefficient of determination is not stable and it is fluctuating between $30 \%$ and $-20 \%$ (see Figure 3).

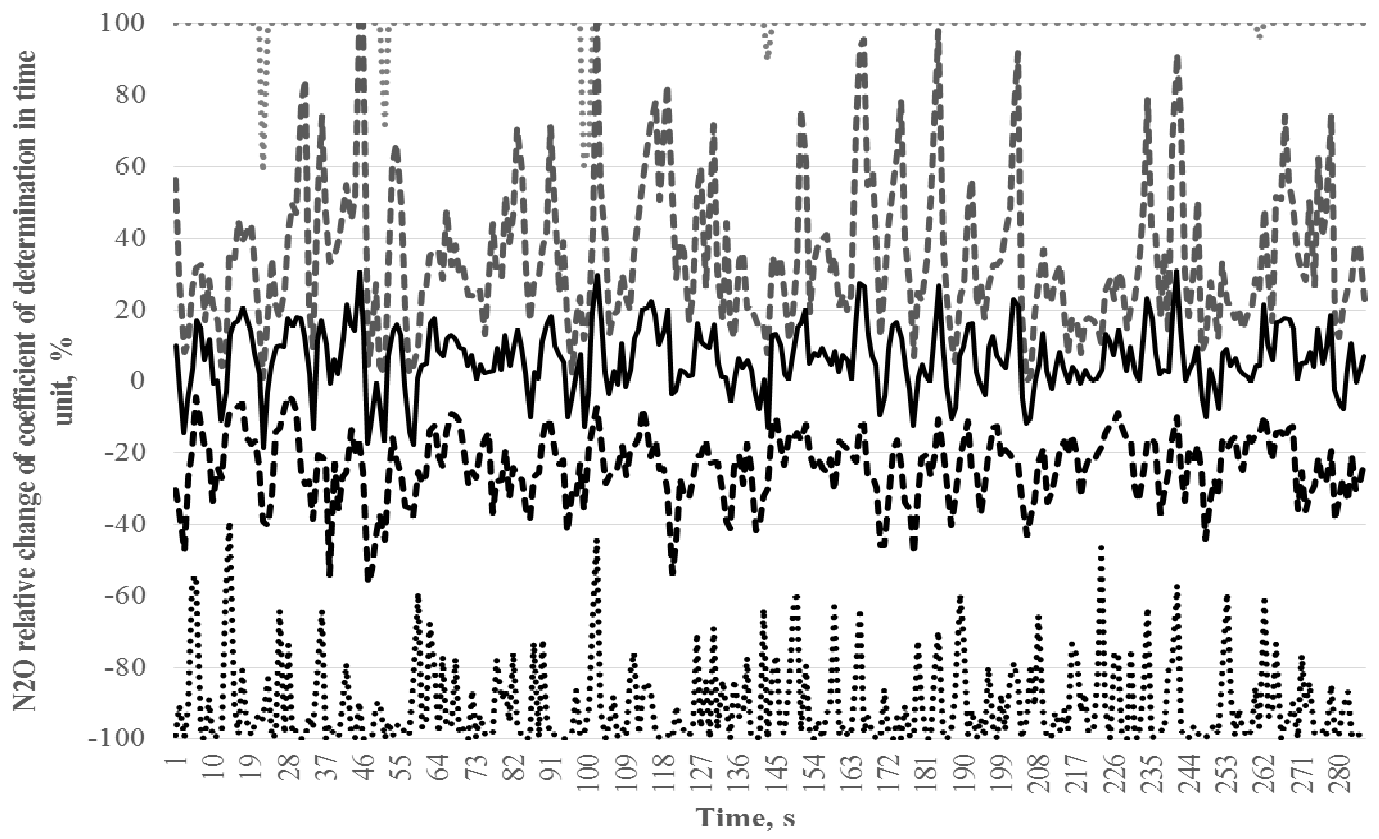

Fig. 3. Relative change of coefficient of determination for $1 \mathrm{~min}$ slope calculation period

The $1^{\text {st }}$ quartile and $3^{\text {rd }}$ quartile are close to mean, but the fluctuaction amplitude is between $100 \%$ and $-60 \%$. The minimal and maximal values are close to $100 \%$ and $-100 \%$. The relative change of the coefficient of determination was analysed for 4 minutes time period. It shows acceptable satbilistation of the change of the determination coefficient and it is in the amplitude from $5 \%$ till $-1 \%$ (see Figure 4). However, there are still high maximal values of the relative slope change.

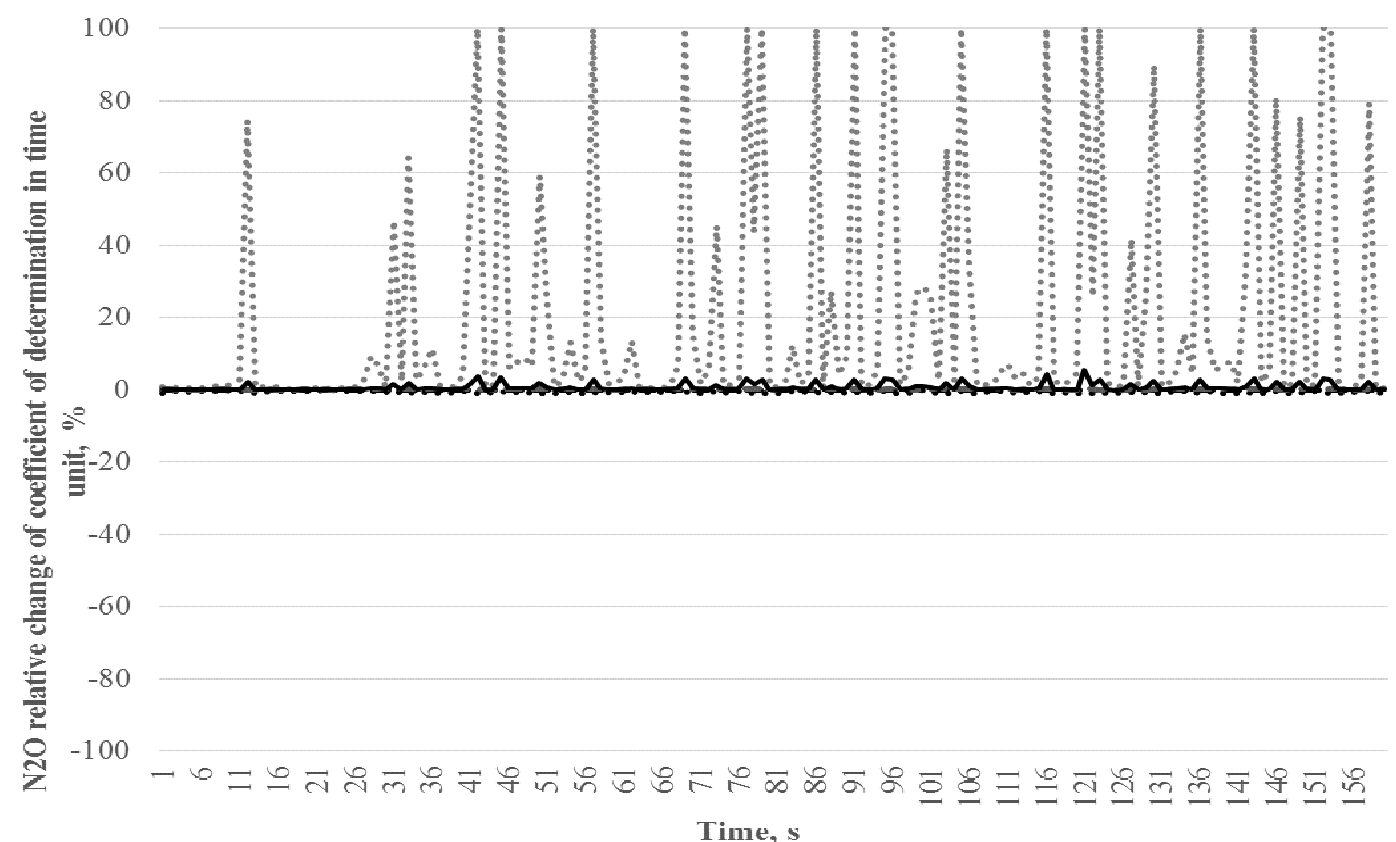

Fig. 4. Relative change of coefficient of determination for $\mathbf{4}$ min slope calculation period

The $1^{\text {st }}$ quartile and $3^{\text {rd }}$ quartile are close to mean, but the fluctuaction amplitude is between $100 \%$ and $-60 \%$. The minimal and maximal values are close to $100 \%$ and $-100 \%$. The relative change of the coefficient of determination was analysed for 4 minutes time period. It shows acceptable stabilistation of the change of the coefficient of determination and it is in the amplitude from $5 \%$ till $-1 \%$ (see Figure 4). However, there are still high maximal values of the relative slope change. The 
acceptable slope calculation start is from 10 till 20 seconds from the measurement start. The first 10 seconds of the measurement are optional to exclude for further calculations.

The acceptable measurement data are presented in Figure 5, where the graph on the left shows the measured concentration with minimal positive slope. However, the trend of concentrations is clearely positive. The graph in the middle presents the slope and $R^{2}$ relation with the slope calculation period $1 \mathrm{~min}$. The graph on the right side presents the slope and $R^{2}$ relation with the slope calculation period $4 \mathrm{~min}$. There is clear correlation between the slope and $R^{2}$. The highest slope values are with higher $R^{2}$.
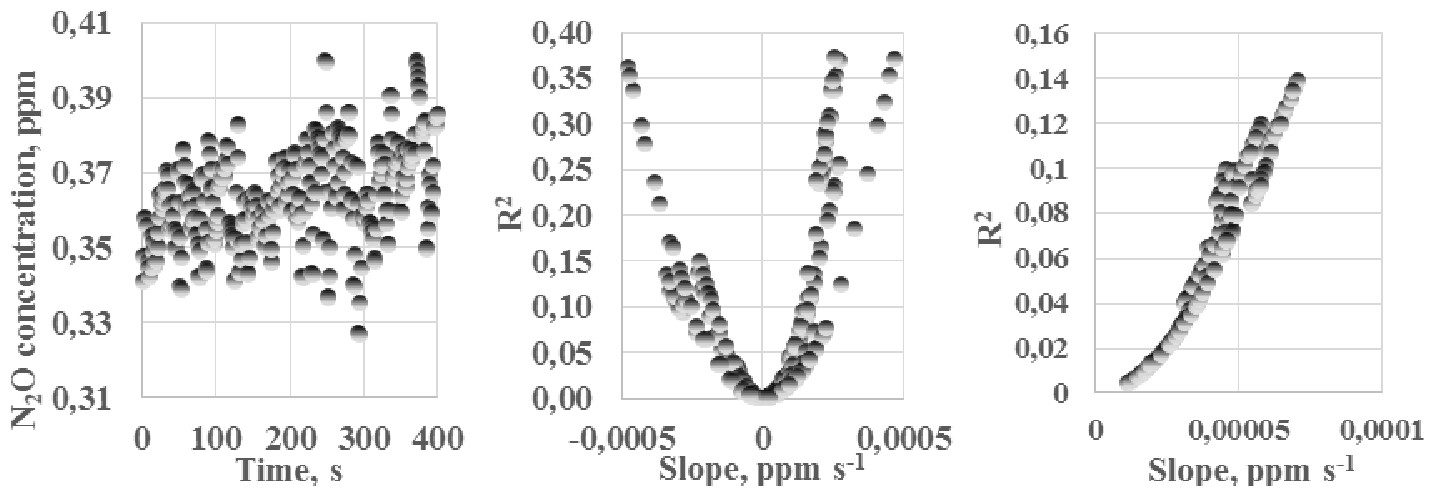

Fig. 5. Acceptable example of measurement (left-measured concentartions; middle $-\boldsymbol{R}^{2}$ and slope relation at 1minute calculation period; right $-R^{2}$ and slope correlation at 4 minute calculation period)

The unacceptable measurement data are presented in Figure 6, where the graph on the left shows the measured concentration with unclear slope. The concentrations fluctuacte, but there is too wide fluctuaction amplitude. The graph in the middle presents the slope and $R^{2}$ relation with the slope calculation period $1 \mathrm{~min}$. The relation is not symmetrical and it shows 3 outliers. The graph on the right side presents the slope and $R^{2}$ relation with the slope calculation period $4 \mathrm{~min}$. There is clear correlation between the slope and $R^{2}$. However, the $\mathrm{N}_{2} \mathrm{O}$ slope is negative or close to 0 .
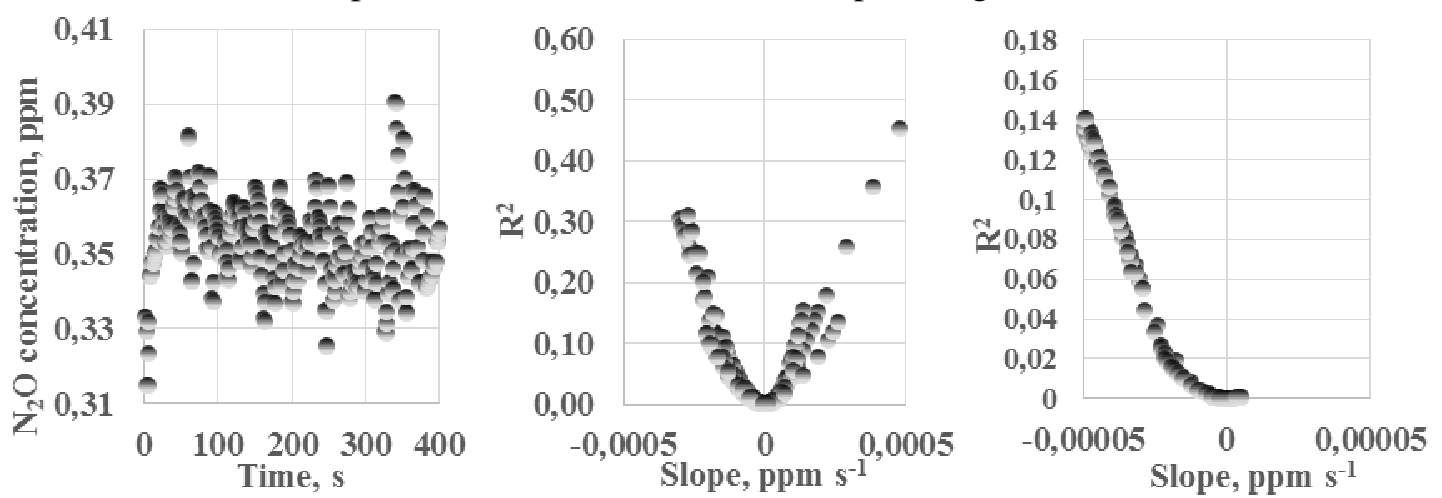

Fig. 6. Unacceptable example of measurement (left-measured concentartions; middle $-\boldsymbol{R}^{2}$ and slope correlation at 1minute calculation period; right $-R^{2}$ and slope correlation at 4 minutes calculation period)

\section{Conclusions}

1. The CRDS device Picarro G2508 can be used for $\mathrm{N}_{2} \mathrm{O}$ emission measurements at laboratory and field conditions. The recirculation system is sensitive to fluctuaction of $\mathrm{N}_{2} \mathrm{O}$ concentrations as well as the concentration of other gases is an important factor.

2. The minimal measurement time is 4 minutes and 10 seconds for $\mathrm{N}_{2} \mathrm{O}$ emissions. The previous timescale can be used for laboratory experiments with the air temperature and soil temperature range from $20^{\circ} \mathrm{C}$ till $30^{\circ} \mathrm{C}$.

3. Each measurement data set has to be veifyed and evaluated before calculation and repeated measurements have to be optional.

4. The multiple slope calculation aproach can be used for slope calculations, where the slope of samples is calculated as average from several slopes. 


\section{References}

1. Hutchinson G.L., Mosier A.R. Improved soil cover method for field measurement of nitrous oxide fluxes. Soil Sci. Soc. Am. J. vol. 45, 1981, pp. 311-315.

2. Pihlatie M.K., Christiansen J.R., Aaltonen H., Korhonen J.F.J., Nordbo A., Rasilo T., Benant, G., Giebels M., Helmy M., Sheehy J., Jones S., Juszczak R., Klefoth R., Lobo-do-Vale R., Rosa A.P., Schreiber P., Serc D., Vicca S., Wolf B., Pumpanen J. Comparison of static chambers to measure CH4 emissions from soils. Agric. For. Meteorol. vol. 171-172, 2013, pp. 124-136.

3. Christiansen J. R., Outhwaite J., Smukler S. M. Comparison of CO2, CH4 and N2O soilatmosphere exchange measured in static chambers with cavity ring-down spectroscopy and gas chromatography. Agricultural and Forest Meteorology, vol. 211, 2015, pp. 48-57.

4. Hensen A., Skiba U., Famulari D. Low cost and state of the art methods to measure nitrous oxide emissions. Environ. Res. Lett. Vol. 8, 2013, pp. 1-10

5. Fleck D., He Y., Alexander C., Jacobson G., Cunningham K.L. Simultaneous soil flux measurements of five gases - N2O, CH4, CO2, NH3, and $\mathrm{H} 2 \mathrm{O}$ - with the Picarro G2508 1-11. Picarro Inc., Santa Clara, CA, USA. 2013. 11 p.[online] [21.03.2017]. Available at: https://picarro.app.box.com/s/z2gpj3hpl11xye9csz6mdpixltc1i5hl.

6. IPCC. Climate Change 2013: The Physical Science Basis. Contribution of Working Group I to the Fifth Assessment Report of the Intergovernmental Panel on Climate Change [Stocker, T. F., D. Qin, G.-K. Plattner, M. Tignor, S. K. Allen, J. Boschung, A. Nauels, Y. Xia, V. Bex and P. M. Midgley (eds.)]. Cambridge University Press, Cambridge, United Kingdom and New York, NY, USA. 2013. 87 p.[online] [21.03.2017] Available at: http://www.climatechange2013.org/images/report/WG1AR5_TS_FINAL.pdf 